IOSR Journal of Engineering (IOSRJEN)

e-ISSN: 2250-3021, p-ISSN: 2278-8719

Vol. 3, Issue 8 (August. 2013), |V2 || PP 51-59

\title{
Effect of alternating current on electrolytic solutions
}

\author{
Parantap Nandi \\ Department—Electrical Engineering, West Bengal University of Technology (WBUT)
}

\begin{abstract}
Electrolysis is always carried out using direct current because here the electrodes have definite polarity. Generally low voltage and high current are preferred. For industrial purposes, an optimum voltage of 9$12 \mathrm{~V}$ and 5-6A is favorable. In most cases metallic electrodes e. $\mathrm{g} \mathrm{Cu}, \mathrm{Fe}, \mathrm{Sn}, \mathrm{Zn}$ are used according to the requirement. Ionization occurs at anode. Hence no bubbles are observed. Towards A.C the behavior of the solution depends mainly on the electrodes. For most metallic electrodes namely $\mathrm{Cu}, \mathrm{Zn}$ the solution behaves much like resistance and the energy is wasted in heating of the solution. Sometimes the solution reaches its boiling point. Aluminum (very cheap and commonly found) acts in a very different manner. Here liberation of $\mathrm{O}_{2}$ and $\mathrm{H}_{2}$ is possible just like D.C along with liberation of heat. While high voltage D.C (220V) is totally unsuitable for electrolysis, 220V A.C can produce useful products. Power consumption is also reasonable. So domestic A.C supply can be used to produce useful products like $\mathrm{O}_{2}, \mathrm{H}_{2}$, different hydroxides and iodine $\left(\mathrm{I}_{2}\right)$ solution. In this paper the basic features of electrolysis using A.C have been outlined based on experiments.
\end{abstract}

Keywords: - A.C; $A l ; C u$; Capacitor.

\section{INTRODUCTION}

In direct current the electrodes have fixed polarity. Anode is always positive and cathode is negative. So cations having positive charge migrate towards cathode and anions towards anode. The discharge or ionization depends on the respective electrode potentials. So the charge which is a product of current and time $(\mathrm{Q}=\mathrm{It})$ is utilized in oxidation or reduction at anode and cathode respectively. As a result, the heat production is almost negligible. The reactions are clearly visible as they are very fast. For e.g. during electrolysis of acidified water with platinum electrodes $\mathrm{H}_{2}$ bubbles at cathode and $\mathrm{O}_{2}$ at anode. The amount of products depends on charge of the ion. For instance 1 Faraday of charge can reduce 1 mole $\mathrm{Ag}^{+}, 1 / 2$ mole $\mathrm{Cu}^{2+}$ and 1/3 mole of $\mathrm{Al}^{3+}$. This in accordance with Faraday's law of electrolysis. All these occur when voltage ranges from 6-12V and current 5-6A (as is used for most industrial purposes). The energy sources are batteries or step down transformers along with rectifier and a good filtration circuit.

High voltage D.C is not used for the following reasons-

a. Nowadays supplies (both domestic and industrial) are A.C.

b. Rectifiers get burnt out at such high voltage due to heating and the circuit gets shorted.

c. High voltage causes dangerous sparking and heating of the solution. The resistance drops with increase in temperature (as the solution is an electrolyte) and current and heat increases further.

d. Filtration of such high voltage D.C is very difficult. The presences of A.C components result in undesired products.

e. As temperature of the solution is beyond control, it causes vaporization of the solution.

f. Temperature sensitive solutions can not be electrolyzed.

A.C has a definite frequency of $\mathbf{5 0 - 6 0 H z}$. When the voltage is stepped down the frequency is unaltered. The electrodes alter their polarity 50 times a second. The heavy ions can not follow such high frequency. So they can't be discharged effectively. As a result the solution acts just like an ordinary resistance. At each electrode $(\boldsymbol{P t})$ small bubbles are noticed due to high mobility of $\boldsymbol{H}^{+}$and $\boldsymbol{O H}^{-}$. They can migrate to the electrodes owing to their high mobility. Hence a mixture of $\mathrm{H}_{2}$ and $\mathrm{O}_{2}$ is formed at each electrode.

High voltage A.C causes a lot of sparking and heating. But unlike D.C it can't produce any products.

If carbon resistors like $.5 K \Omega, 1 K \Omega$ or above are used to control current $(\mathrm{I}=V / R)$ it gets burnt out very quickly due to very large heating $\left(\boldsymbol{H}=\boldsymbol{I}^{2} \boldsymbol{R} \boldsymbol{t}\right)$.Small resistances on the other hand produce no effect. As pure water is a very bad conductor of electricity, a definite volume of water $(200 \mathrm{ml}$.) may be connected in series to limit the value of current. But it too isn't able to produce any marked effect. This is due to the high electric field applied; the water molecules are forced to conduct. But still if A.C is passed for a long time, (by turning the switch on and off repeatedly) the clear solution develops color which depends on the electrode. The sparking results in the production of radio waves which can be detected by a radio receiver placed nearby. The sparks are highly luminous. The intensity almost resembles the sparks produced in arc welding. Their color though mostly golden yellow vary with the salt added. For e.g. if the solution contains $\mathrm{Ca}\left(\mathrm{NO}_{3}\right)_{2}$, sparks are tinged with red. This may be compared with the emission spectrum of $\boldsymbol{C a}^{2+}$ the discussion of which is beyond the scope of this paper. 
But unlike resistors, capacitors with small capacitances $(<3 \boldsymbol{\mu F})$ and high voltage rating $(440 \mathrm{~V})$ can limit the current and prevent sparking and excessive vigor of the reaction. They are not destroyed. However they must be $\boldsymbol{P V C}$ or oil filled capacitors. These are commonly used in ceiling fans and are cheap. On the other hand electrolytic capacitors of comparable capacitances $(4.7 \boldsymbol{\mu F})$ are totally unsuitable for the said purposes because they contain weak electrolytes like sodium borate as one of the plates and behave just like solutions under an A.C field. So they get very hot and give smoke. Sometimes explosion takes place. The PVC or oil filled capacitors provide good regulation. They also introduce a phase difference between voltage and current in the circuit; the current leading the voltage by certain phase angle $\left(\boldsymbol{m o s t l y}>\mathbf{6 0} 0^{\circ}\right)$. So active power and hence heat production is much less.

Common electrodes like $\mathrm{Cu}, \mathrm{Fe}$ and $\mathrm{Zn}$ all give a mixture of $\boldsymbol{H}_{2}$ and $\boldsymbol{O}_{2}$ at each electrode. This is the case for pure water. If salt is added, the solution becomes tinged due to ionization of the electrodes. For instance $\boldsymbol{K C l}$ solution becomes greenish when electrolyzed with $\mathrm{Cu}$ electrodes.

But Al shows different properties like-

a. The reaction is fast enough like low voltage D.C.

b. $\mathrm{O}_{2}$ and $\mathrm{H}_{2}$ liberation are higher.

c. A large amount of foam is observed.

d. It gives $\boldsymbol{I}_{2}$ solution from $\boldsymbol{K} \boldsymbol{I}$ solution which is not obtained from other electrodes.

A.C also gives reddish brown solution of ferric acetate with $\mathrm{Pb}\left(\mathrm{CH}_{3} \mathrm{COO}\right)_{2}$ solution.

A very special feature of A.C electrolysis is the color of the solution, which is different from electrolysis using direct current.

Apparatus specifications:

A. Capacitor Type-PVC/Oil filled $440 V-2.5 \mu F \pm 5 \%$.

B. A.C supply (domestic).

C. Electrodes- $\mathrm{Cu}, \mathrm{Fe}, \mathrm{Zn}, \mathrm{Al}$, graphite.

D. Electrolytes- $\mathrm{KCl}, \mathrm{FeCl}_{3}, \mathrm{KI}, \mathrm{Pb}\left(\mathrm{CH}_{3} \mathrm{COO}\right)_{2 .} 3 \mathrm{H}_{2} \mathrm{O}, \mathrm{C}_{10} \mathrm{H}_{14} \mathrm{~N}_{2} \mathrm{Na}_{2} \mathrm{O}_{8} .2 \mathrm{H}_{2} \mathrm{O}$

E. 4 diodes Type-IN4007.

F. Digital millimeter having good precision.

G. $100 \mathrm{ml} . \mathrm{H}_{2} \mathrm{O}$.

\section{EXPERIMENTAL}

The experiment was started with high voltage D.C obtained from a bridge rectifier circuit (consisting of 4 diodes).

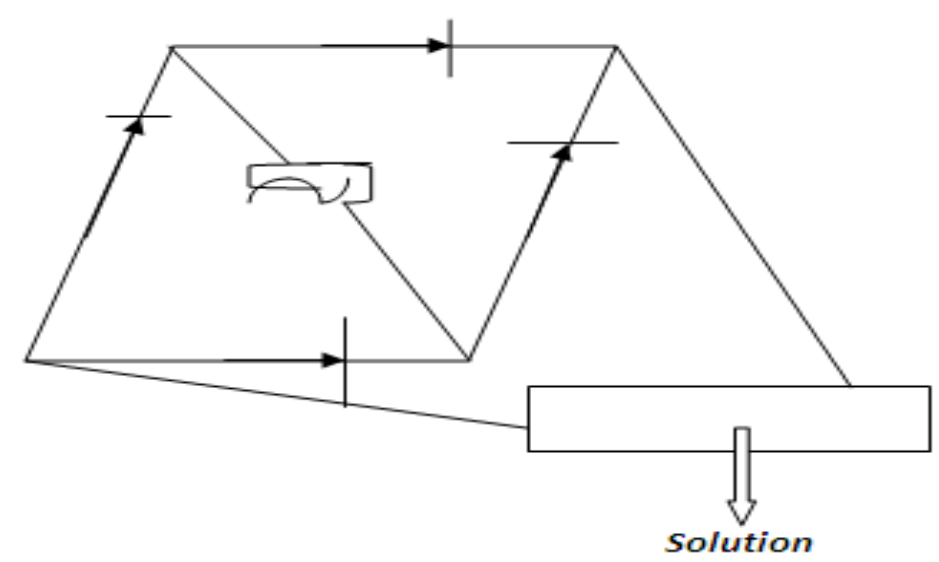

Figure 1

- The curved line represents A.C supply $(210 \mathrm{~V})$

Neutral water (free from salts and other impurities) was electrolyzed with $\mathrm{Cu}$ electrodes.

a. The reaction was extremely fast.

b. Sparks were absent.

c. Very rapidly water reached its boiling point. Much of the liquid spurt out.

d. Yellowish blue insoluble mass appeared.

The same experiment was repeated with $\mathrm{KCl}$ solution. In this case brilliant sparks tinged with pink were observed. Yellowish brown insoluble mass was obtained. The reaction was so violent that current had to be switched off. If low voltage direct current were used, the color would be pale blue i.e. that of $\boldsymbol{C u}(\boldsymbol{O H})_{2}$.

The above experiments were carried out with $220 \mathrm{~V}$ A.C. No color was observed in case of pure water while in case of case of $\mathrm{KCl}$ solution the solution was tinged with green. Sparks were noticed for $\mathrm{KCl}$ solution. 
An apparatus was set up as follows:-

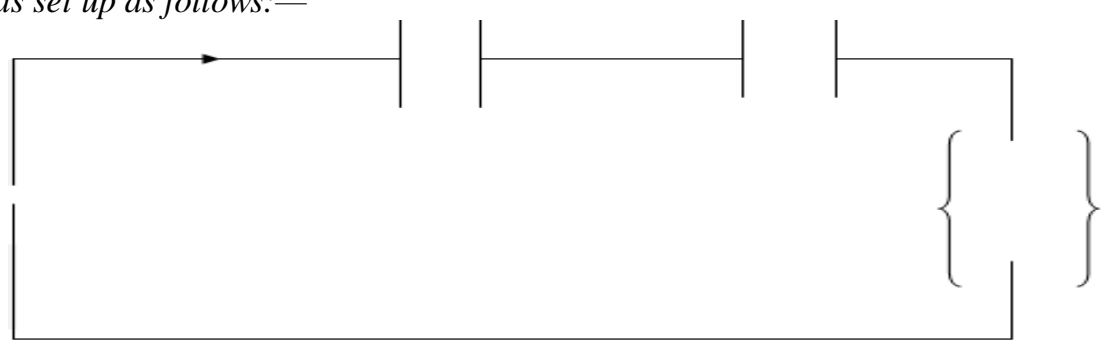

Figure 2

- The parallel vertical lines represent two capacitors in series.

- The line with the arrow represents the live wire.

- The braces indicate the solution.

\section{Experiment no. 1}

Pure water (100 ml.) was electrolyzed using $\mathrm{Cu}$ electrodes. Bubbles were observed at both electrodes. Pale blue color was observed at the neutral. Heat generated was much less. Voltage drop across water was $150 \mathrm{~V}$.

\section{Experiment no. 2}

$100 \mathrm{ml}$. water was electrolyzed using Fe electrodes. Bubbles of $\mathrm{H}_{2}$ and $\mathrm{O}_{2}$ were observed at both electrodes. Voltage drop across water was $50 \mathrm{~V}$.

\section{Experiment no. 3}

The experiment was repeated with $\mathrm{Zn}$. Bubbles were observed. Voltage drop across water 40V.

\section{Experiment no. 4}

Graphite electrodes used to electrolyze neutral water. Voltage drop across water $87.5 \mathrm{~V}$.

\section{Experiment no. 5}

$\mathrm{Al}$ electrodes were used in the same experiment. More bubbles than the above cases appeared. A lot of foam was formed. Voltage drop across water was $75 \mathrm{~V}$.

\section{Experiment no.6}

$\mathrm{KCl}$ solution (formed by dissolving $5 \mathrm{~g}$. in $100 \mathrm{ml} . \mathrm{H}_{2} \mathrm{O}$ ) was taken instead of pure water. One by one $\boldsymbol{C u}, \mathbf{F e}, \mathbf{A l}, \mathbf{Z n}$ and graphite electrodes were used. The voltage drop across the solution was recorded in each case. The current was also recorded. Small bubbles were observed at the electrodes. In case of $\boldsymbol{C} \boldsymbol{u}$ pale blue insoluble mass developed mostly at the neutral. Slowly the solution developed a greenish tinge. In case of Fe the solution developed reddish brown color. In both cases precipitates were not obtained. The evolution of $\mathrm{H}_{2}$ and $\mathrm{O}_{2}$ bubbles stopped after a certain period. For $\mathrm{Al}$ a lot of foam was generated. The evolution of bubbles, unlike the other electrodes did not stop. Graphite gave bubbles at a slower rate.

\section{Experiment no.7}

$\mathrm{FeCl}_{3}$ solution was electrolyzed with Fe electrodes. Bubbles were observed at both electrodes. The solution remained clear and retained the original color of $\mathrm{FeCl}_{3}$. $\mathrm{Zn}$ was not used as it displaces $\mathrm{Fe}^{3+}$ from its solution. In case of Al bubbles were noticed along with the appearance of foam on the solution's surface. Fe particles were formed in a small amount. This was not noticed when the same Al was dipped in the solution without application of electric field.

\section{Experiment no.8}

$\mathrm{Pb}\left(\mathrm{CH}_{3} \mathrm{COO}\right)_{2} .3 \mathrm{H}_{2} \mathrm{O}$ solution was electrolyzed using Fe electrodes. For the first 2 hours nothing could be seen except the evolution of small bubbles at both electrodes. But after that the solution rapidly started turning brown. Very soon within one hour it changed dark brown. Possible mechanism could have been

$\mathrm{Pb}\left(\mathrm{CH}_{3} \mathrm{COO}\right)_{2}+2 \mathrm{H}_{2} \mathrm{O} \rightarrow 2 \mathrm{CH}_{3} \mathrm{COOH}+\mathrm{Pb}(\mathrm{OH})_{2} \downarrow$

$\mathrm{Fe}+3 \mathrm{CH}_{3} \mathrm{COOH} \rightarrow \mathrm{Fe}\left(\mathrm{CH}_{3} \mathrm{COO}\right)_{3}+3 / 2 \mathrm{H}_{2}$

But when Fe was heated in a solution of lead acetate the solution gained the same color after about 1 full day. Moreover it was not as dark as the one formed on application of A.C field. Spikes of metallic $\mathrm{Pb}$ developed on the Fe electrodes. 
The above experiment (no. 8) was repeated with Al electrodes. The solution turned colorless. There was no precipitate.

\section{Experiment no.10}

A very dilute solution of $\mathrm{KI}$ was electrolyzed using $\mathrm{Cu}, \mathrm{Fe}, \mathrm{Al}, \mathrm{Zn}$ and graphite electrodes. Except $\boldsymbol{A l}$ all other electrodes showed same results as in $\mathrm{KCl}$ solution. But $\mathrm{Al}$ gave yellow colored solution. Foams were visible on top of the solution. The yellow color disappeared when the solution was kept exposed to air. The yellow solution resembled $\boldsymbol{I}_{2}$ solution.

\section{OBSERVATIONS}

As stated theoretically pure $\mathrm{H}_{2} \mathrm{O}$ is a very weak electrolyte. But a large electric field can make it conduct. A voltage of $210 \mathrm{~V}$ can make $100 \mathrm{ml}$. water conduct as much as .45A. So its resistance is only $466.66 \Omega$ But D.C at the same voltage can't be used for electrolysis like sparking, filtration problems. It also gives undesired products like $\boldsymbol{C} \boldsymbol{u}_{2} \boldsymbol{O}$ in case of $\mathrm{Cu}$ electrodes and $\mathrm{KCl}$ solution. Resistors are unable to control this current.

A.C just like D.C causes large amount of heating and sparking (in case of solutions). But it can be controlled with the help of PVC or oil filled capacitors. The circuit being capacitive, current leads the voltage and active power (VICos $\boldsymbol{\phi})$, which is responsible for heating is less. Under A.C conditions any solution gives $\mathrm{O}_{2}$ and $\mathrm{H}_{2}$ at each electrode. As a result, bubbles are observed. The table gives the respective observations:-

Table No. 1

\begin{tabular}{|c|c|c|c|c|}
\hline $\begin{array}{l}\text { Solution } \\
\text { used }\end{array}$ & Electrode & Color of solution & Precipitate & Color in case of D.C \\
\hline $\mathrm{H}_{2} \mathrm{O}$ & $\begin{array}{l}\mathrm{Cu}, \mathrm{Fe}, \mathrm{Al}, \\
\mathrm{Zn}, \text { graphite }\end{array}$ & Colorless & Nil & $\begin{array}{l}\text { Pale blue, Dirty green, white, gelatinous white } \\
\text { and black particles respectively }\end{array}$ \\
\hline $\mathrm{KCl}$ & $\mathrm{Cu}$ & Greenish & Nil & Pale blue precipitate \\
\hline $\mathrm{KCl}$ & $\mathrm{Fe}$ & $\begin{array}{l}\text { Reddish yellow } \\
\text { brown }\end{array}$ & $\begin{array}{l}\text { Very negligible } \\
\text { amount of floating } \\
\text { mass }\end{array}$ & Dirty green precipitate \\
\hline $\mathrm{KCl}$ & $\mathrm{Al}$ & Colorless & $\begin{array}{l}\text { Large amount of } \\
\text { foam generated }\end{array}$ & Large amount of white insoluble mass \\
\hline $\mathrm{KCl}$ & $\mathrm{Zn}$ & Colorless & Nil & Gelatinous white mass \\
\hline $\mathrm{KCl}$ & Graphite & Colorless & Nil & $\begin{array}{l}\text { Soapy solution with black particles of carbon } \\
\text { along with smell of } \mathrm{Cl}_{2}\end{array}$ \\
\hline KI & $\mathrm{Cu}$ & Greenish & Nil & Pale blue precipitate \\
\hline KI & $\mathrm{Fe}$ & Yellowish brown & Almost nil & Dirty green precipitate \\
\hline KI & $\mathrm{Al}$ & Yellow & $\begin{array}{l}\text { White foam on the } \\
\text { surface of the } \\
\text { solution }\end{array}$ & Yellow foamy solution \\
\hline $\begin{array}{l}\mathrm{Pb}\left(\mathrm{CH}_{3} \mathrm{COO}\right. \\
)_{2} .3 \mathrm{H}_{2} \mathrm{O}\end{array}$ & $\mathrm{Cu}$ & $\begin{array}{l}\text { Bluish (after } \\
\text { several hours) }\end{array}$ & Nil & Blue solution containing dissolved $\mathrm{Cu}^{2+}$ \\
\hline $\begin{array}{l}\mathrm{Pb}\left(\mathrm{CH}_{3} \mathrm{COO}\right. \\
)_{2} .3 \mathrm{H}_{2} \mathrm{O}\end{array}$ & $\mathrm{Fe}$ & Dark brown & $\begin{array}{ll}\text { Silvery black } \mathrm{Pb} \\
\text { spikes formed on } \\
\text { Fe surface }\end{array}$ & Same as in A.C \\
\hline $\begin{array}{l}\mathrm{Pb}\left(\mathrm{CH}_{3} \mathrm{COO}\right. \\
)_{2} .3 \mathrm{H}_{2} \mathrm{O}\end{array}$ & $\mathrm{Al}$ & Colorless & $\begin{array}{ll}\text { Nil } & \text { (foam } \\
\text { negligible) }\end{array}$ & Same as in A.C \\
\hline
\end{tabular}

The possible reactions for A.C are:-

$4 \mathrm{OH}^{-}-4 e^{-} \rightarrow 4 \mathrm{OH} \rightarrow 2 \mathrm{H}_{2} \mathrm{O}+\mathrm{O}_{2}$

$2 \mathrm{H}^{+}+2 e^{-} \rightarrow \mathrm{H}_{2}(0.00)$

$\mathrm{Cu}-2 e^{-} \rightarrow \mathrm{Cu}^{2+}(-.3419)$

$\mathrm{Fe}-3 e^{-} \rightarrow \mathrm{Fe}^{3+}$ (.037)

$\mathrm{Pb}^{2+}+2 e^{-} \rightarrow \mathrm{Pb}(-.1262)$

$2 I-2 e^{-} \rightarrow I_{2}(-.5355)$

The figures in the braces indicate the $\mathrm{E}^{\circ} / \mathrm{V}$

These reflect that the color obtained in case of A.C is different from D.C electrolysis in some cases like $\mathrm{Cu}$ or Fe in $\mathrm{KCl}$ solution. $\mathrm{Al}$ reacts in a different manner in $\mathrm{KI}$ solution. Here I'migrate to anode and discharged as $2 \boldsymbol{I}^{-\mathbf{- 2}} \mathbf{-}$ $\rightarrow \boldsymbol{I}_{2}$. Also the reaction is similar to direct current. A systematic recording of the voltage drops, currents and phase angles are given in the tables below:- 
Table No. 2 (for pure water)

\begin{tabular}{|l|l|l|l|l|}
\hline Electrode_used & $\underline{\mathbf{V}}_{\mathbf{W}}$ & $\underline{\underline{V}}_{\mathrm{C}}$ & $\mathbf{I}$ & $\square$ \\
\hline $\mathrm{Cu}$ & $150 \mathrm{~V}$ & $82.5 \mathrm{~V}$ & $68.3 \mathrm{~mA}$ & $47.72^{\circ}$ \\
\hline $\mathrm{Fe}$ & $50 \mathrm{~V}$ & $103.5 \mathrm{~V}$ & $86.4 \mathrm{~mA}$ & $76.42^{\circ}$ \\
\hline $\mathrm{Al}$ & $75 \mathrm{~V}$ & $99 \mathrm{~V}$ & $80.4 \mathrm{~mA}$ & $69.255^{\circ}$ \\
\hline $\mathrm{Zn}$ & $40 \mathrm{~V}$ & $108 \mathrm{~V}$ & $86 \mathrm{~mA}$ & $79.508^{\circ}$ \\
\hline Graphite & $87.5 \mathrm{~V}$ & $96.3 \mathrm{~V}$ & $83.9 \mathrm{~mA}$ & $65.56^{\circ}$ \\
\hline
\end{tabular}

Table No.3 (for $\mathrm{KCl}$ solution)

\begin{tabular}{|c|c|c|c|c|}
\hline Electrode used & $\underline{\mathbf{V}}_{\mathrm{W}}$ & $\mathbf{V}_{\mathrm{C}}$ & I & $\square$ \\
\hline $\mathrm{Cu}$ & $3.5 \mathrm{~V}$ & $106.2 \mathrm{~V}$ & $87.6 \mathrm{~mA}$ & $89.055^{\circ}$ \\
\hline $\mathrm{Fe}$ & $7.5 \mathrm{~V}$ & $112.4 \mathrm{~V}$ & $86.7 \mathrm{~mA}$ & $88.089^{\circ}$ \\
\hline $\mathrm{Al}$ & $6 \mathrm{~V}$ & 112.4 & $87.4 \mathrm{~mA}$ & $88.47^{\circ}$ \\
\hline $\mathrm{Zn}$ & $2.5 \mathrm{~V}$ & $111.6 \mathrm{~V}$ & $88 \mathrm{~mA}$ & $89.35^{\circ}$ \\
\hline Graphite & $24 \mathrm{~V}$ & 106.1 & $86.6 \mathrm{~mA}$ & $83.54^{\circ}$ \\
\hline
\end{tabular}

Here symbols used are

$V_{C}=$ Voltage across each capacitor

$V_{W}=$ Voltage drop across water

$I=$ Current in the circuit

$\square=$ Phase angle (in degrees)

Cos $\square=$ Power factor

$\cos \phi=\mathrm{V}_{\mathrm{W}} / \square\left(\mathrm{V}_{\mathrm{W}}^{2}+\mathrm{V}_{\mathrm{C}}^{2}\right)$

$=$ Square root

The graphs have been plotted as $\mathrm{Cu}, \mathrm{Al}, \mathrm{Zn}, \mathrm{Fe}$ and graphite

We notice that phase angle varies with the electrode used and is highest for $\mathrm{Zn}$ in both cases. When voltage drop across water is plotted with respect to current:-

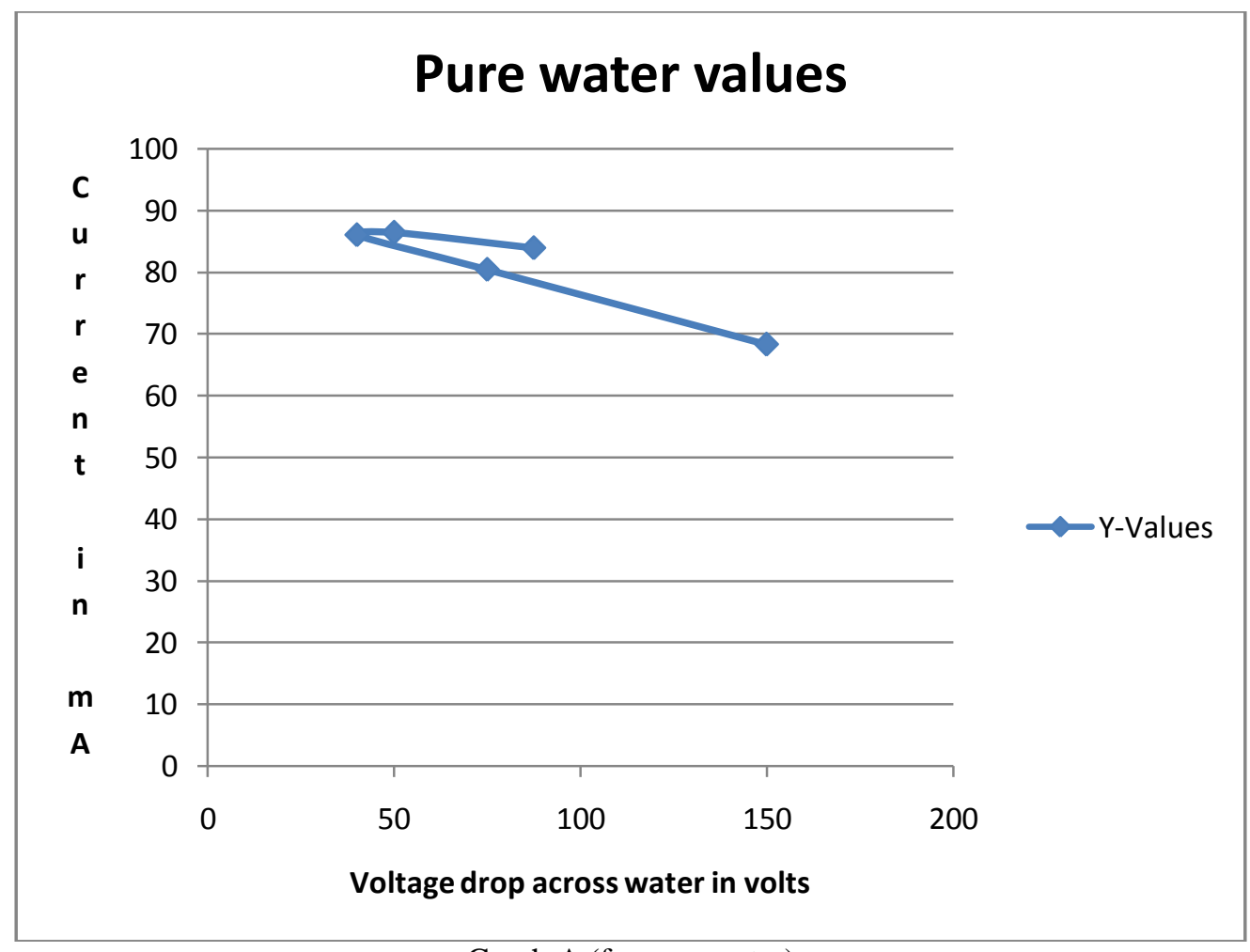

Graph A (for pure water) 

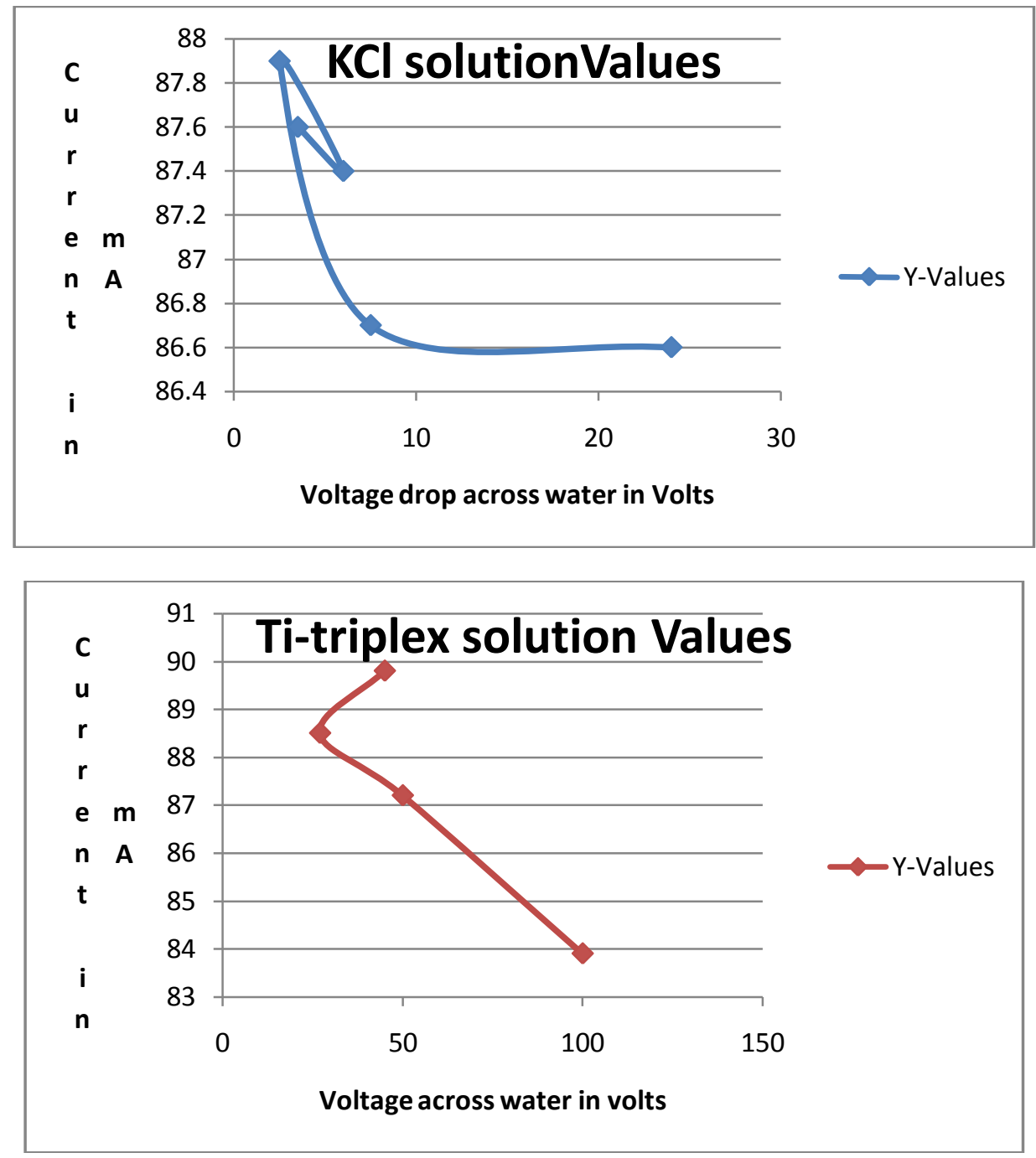

In the 3 graphs given above the curves are almost straight with a negative slope for pure water, hyperbolic for $\mathrm{KCl}$ solution and irregular in shape for Ti-triplex solutions. But all show a decrease in current with increase in potential across water.

Taking voltage drop across the solution and corresponding current with $\mathrm{Cu}$ electrodes as reference, a plot between change of current with change of voltage is given below:-

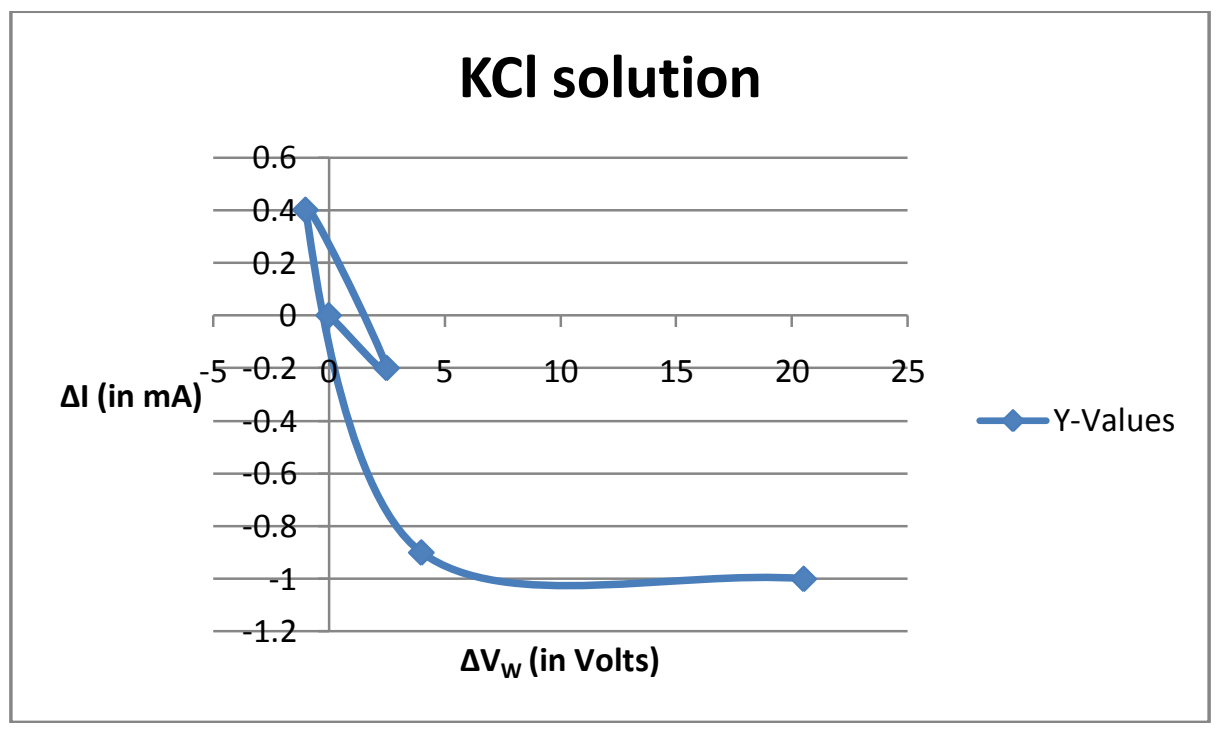




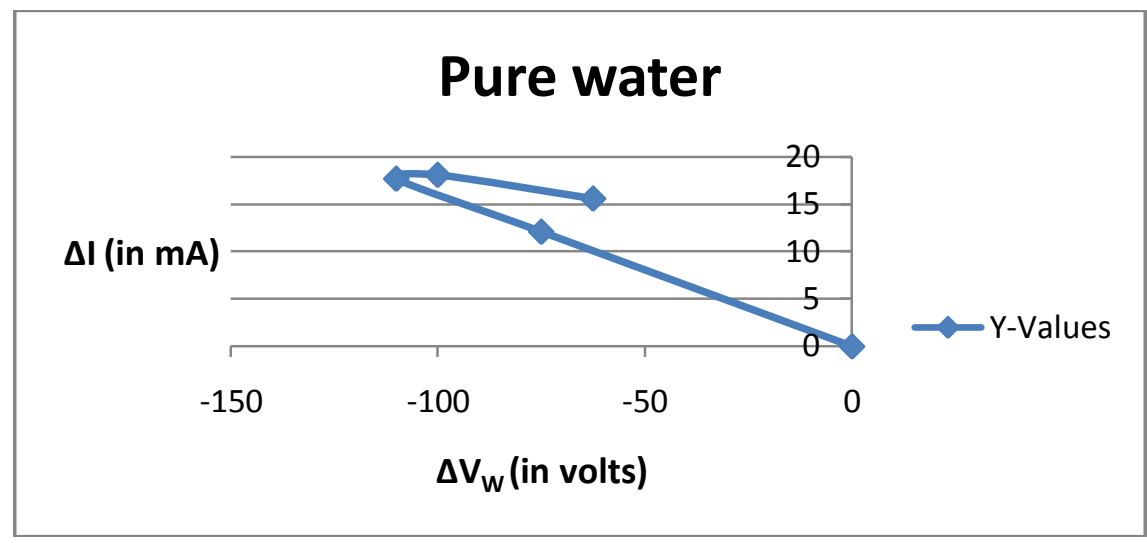

Also on plotting a curve between current and phase angle for $\mathrm{KCl}$ solution-

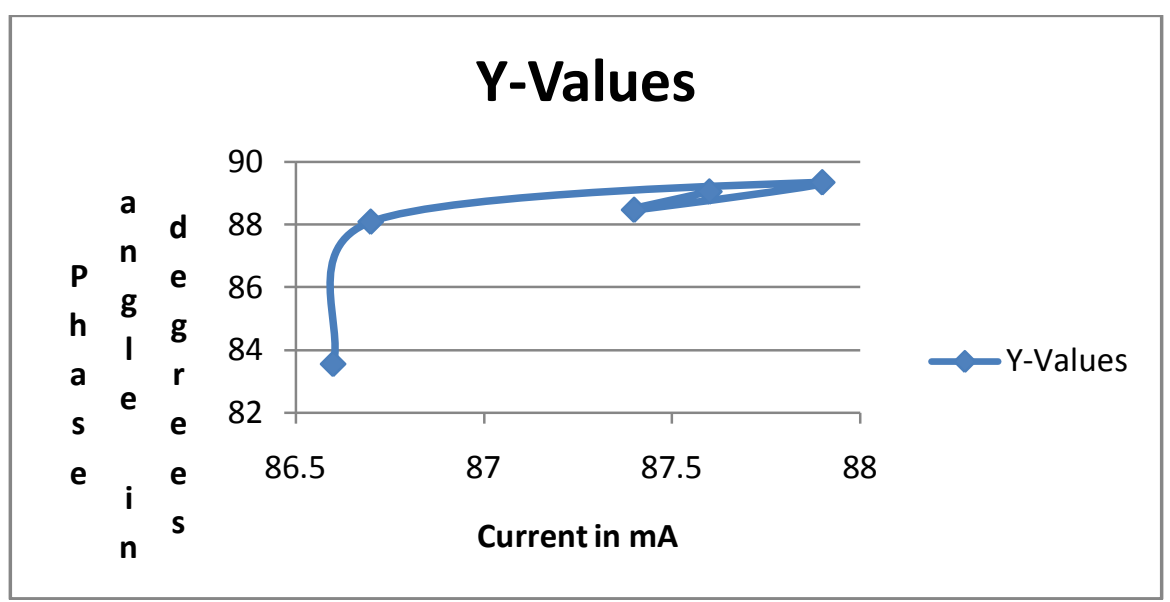

The shape is highly unpredictable. But it reveals that for high current phase angle is also high and therefore power factor is very small. For e.g.:-

From the table no.3 for $\mathrm{Cu}-$

$Q=I t$ (where $t$ is the time)

$I=87.6 \mathrm{~mA}, t=60$ seconds

$Q=54.46 \mu C$

Amount of $\mathrm{Cu}$ that should have ionized $=54.46 * 10^{-6} * .5 * 63.5=1.729 \mathrm{mg}$

Amount of $\mathrm{Cu}(\mathrm{OH})_{2}=(97.5 / 63.5) * 1.729 * 10^{-3}=2.65 \mathrm{mg}$

Neglecting evaporation of the liquid, increase in mass of the $100 \mathrm{ml}$. in 1 hour must be $=2.65 * 60=159 \mathrm{mg} \approx 160 \mathrm{mg}$

(in case of direct current)

But increase in mass was found to be only $50 \mathrm{mg}$.

So efficiency in A.C electrolysis (in comparison to D.C) $=(50 / 160) * 100=31.25 \%$

Power $=$ VICos $\phi=212.42 * 87.6 * 10^{-3} * .016=.297 \mathrm{~W}$

Complex power $=18.6 \mathrm{VA}$

Therefore power consumption is very small $(<20 \mathrm{VA})$.

\section{RESULTS AND DISCUSSIONS}

High voltage alternating current can make water molecules conduct but lead to vigorous reactions with intense heating along with the generation of radio waves. But the reaction can be controlled with the help of capacitors. Electrolytic capacitors are unsuitable as they contain boric acid or sodium borate as electrolytes which get heated up and explode. PVC or oil filled capacitors specialized for A.C circuits and motor (like ceiling fans) can control current and electrolysis can be carried out. Some important results are:-

A. $\mathrm{O}_{2}$ and $\mathrm{H}_{2}$ are always formed at each electrode.

B. Metal ionization like formation of $\mathrm{Cu}^{2+}$ and $\mathrm{Fe}^{3+}$ is slower than direct current.

C. Precipitates are generally not formed during electrolysis using A.C unlike D.C.

D. The color of the solution in case of A.C is different from D.C.

E. Evolution of bubbles at the electrodes is not continuous except for Al. After a certain concentration, the bubbles stop. 
F. In Al bubbles are evolved continuously and a lot of foam is generated which remain on the solution's surface.

G. Voltage drop across the solution is not fixed and is dependent on electrodes.

$\mathrm{H}$. Voltage across any solution is least in case of $\mathrm{Zn}$. Hence phase angle is highest and power factor least for $\mathrm{Zn}$ electrodes.

I. Phase angle gets closer to $\mathbf{9 0}{ }^{\circ}$ with increase in current.

J. Al gives identical reaction at in electrodes if A.C is used instead of D.C in a solution of KI. In both cases $\mathrm{I}_{2}$ solution is formed along with a lot of foam.

K. Synthesis of ferric acetate can be hastened when an alternating field is applied.

L. Though difference in magnitudes of currents is very small, the voltage difference across the solution is considerably large.

M. While in D.C metal ionization occurs at anode, in A.C it occurs mostly at the neutral. E.g. when $\mathrm{KCl}$ solution is electrolyzed using $\mathrm{Cu}$ electrodes under A.C conditions, blue color is observed at neutral to a greater extent than the live terminal.

$\mathrm{N}$. The power consumption is very small.

O. With increase in current in the circuit voltage drop across the solution decreases.

$\boldsymbol{P}$. The shape of $\boldsymbol{I}-\boldsymbol{V}$ curve and the corresponding $\Delta \boldsymbol{I}-\Delta \boldsymbol{V}$ curve are identical i.e. both are hyperbolic for $\boldsymbol{K C l}$ solution and a straight line for pure water.

\section{CONCLUSIONS}

A.C when controlled by capacitor can yield certain useful products like $\mathrm{Fe}\left(\mathrm{CH}_{3} \mathrm{COO}\right)_{3}, \mathrm{I}_{2}$. In some cases it differs from D.C while in others it behaves just like D.C. The current varies mostly between $80-90 \mathrm{~mA}$. The phase angle is not constant and varies with the electrode used. It is highest for $\mathbf{Z n} . \mathrm{O}_{2}$ and $\mathrm{H}_{2}$ are obtained in all cases. The appearance of bubbles stops after a certain period. But only Al gives bubbles continuously. Hydroxides obtained at the neutral are more in amount than at the live terminal. The color of the solution in case of A.C is different in comparison to D.C. Useful products like ferric acetate, aluminium acetate, $I_{2}$ solution and $\mathrm{O}_{2} \mathrm{H}_{2}$ mixture can be obtained using A.C electrolysis. In these reactions the rate is also almost same as that in direct current.

\section{ACKNOWLEDGEMENTS}

This work has been encouraged and supported by Mr. Pannag Bhusan Nandi, Divisional Accounts Officer Grade 1; Government of India.

\section{REFERENCES}

[1]. The electrode reactions are taken from

[2]. The electrode potentials are taken from ELECTROCHEMICAL SERIES Petr Vany'sek (2000 by CRC PRESS LLC) 